\title{
Outcomes of oesophageal variceal bleeding among patients with atrial fibrillation: a propensity-matched analysis of a nationwide inpatient sample
}

Pavani Garlapati ${ }^{1}$, Ebad Ur Rahman², Vijay Gayam¹, Muchi Ditah Chobufo ${ }^{1}$, Farah Fatima ${ }^{3}$, Arfaat M. Khan ${ }^{4}$, Mohamed Suliman ${ }^{5}$, Ellen A. Thompson ${ }^{5}$, Mehiar El-Hamdani ${ }^{5}$, Wilbert S. Aronow ${ }^{6}$

${ }^{1}$ Interfaith Medical Centre Brooklyn, NY, USA

${ }^{2}$ St. Mary's Medical Centre, Huntington, WV, USA

${ }^{3}$ Deccan College of Medical Sciences, Hyderabad, India

${ }^{4}$ Henry Ford Health System, Detroit, MI, USA

${ }^{5}$ Marshall University, Huntington, WV, USA

${ }^{6}$ Westchester Medical Centre and New York Medical College, Valhalla, NY, USA

Submitted: 17 August 2020

Accepted: 23 August 2020

Arch Med Sci Atheroscler Dis 2020; 5: e255-e262

DOI: https://doi.org/10.5114/amsad.2020.98949

Copyright $@ 2020$ Termedia \& Banach

\section{Abstract}

Introduction: We aimed to determine the influence of atrial fibrillation (AF) on mortality, morbidity, length of hospital stay, and resource utilisation in patients with oesophageal variceal bleeding (OVB).

Material and methods: The National Inpatient Sample database (2016 and 2017) was used for data analysis using the International Classification of Diseases, Tenth Revision codes to identify patients with the principal diagnosis of OVB and AF. We assessed the all-cause in-hospital mortality, morbidity, predictors of mortality, length of hospital stay (LOS), and total costs between propensity-matched groups of OVB with AF vs. OVB alone.

Results: We identified 80,325 patients with OVB, of whom 4285 had OVB with $A F$, and 76,040 had OVB only. The in-hospital mortality was higher in OVB with AF (OR $=1.4,95 \% \mathrm{Cl}: 1.09-1.83 ; p<0.001)$. OVB with AF had higher odds of sepsis ( $\mathrm{OR}=1.4,95 \% \mathrm{Cl}: 1.1-1.8 ; p=0.007)$, acute kidney injury $(\mathrm{OR}=1.2,95 \% \mathrm{Cl}: 1.12-1.32 ; p<0.001)$, and mechanical ventilation $(\mathrm{OR}=1.2,95 \% \mathrm{Cl}: 1.12-1.32 ; p<0.001)$. Advanced age $(\mathrm{OR}=1.06,95 \% \mathrm{Cl}$ : $1.05-1.07 ; p<0.001)$, congestive heart failure $(\mathrm{OR}=1.7,95 \% \mathrm{Cl}: 1.3-2.3$; $p<0.001)$, coronary artery disease $(\mathrm{OR}=1.4,95 \% \mathrm{Cl}: 1.03-1.92 ; p=0.02)$, and sepsis $(\mathrm{OR}=1.3,95 \% \mathrm{Cl}: 1.06-1.70 ; p=0.01)$ were identified as predictors of mortality in OVB with AF. Mean LOS (7.5 \pm 7.4 vs. $6.0 \pm 7.2, p<0.001)$ and mean total costs $(\$ 25,452$ vs. $\$ 21,109, p<0.001)$ were also higher. Conclusions: In this propensity-matched analysis, OVB with AF was associated with higher odds of in-hospital mortality, sepsis, acute kidney injury, and mechanical ventilation.

Key words: oesophageal variceal bleeding, atrial fibrillation, National Inpatient Sample, propensity-matched outcomes

\section{Introduction}

Cirrhosis is a prominent cause of mortality in the United States [1]. In 2010, cirrhosis resulted in an estimated 49,500 deaths, which represented a significant increase from 35,500 deaths decades ago [2]. Most common disease-specific complications such as oesophageal varices,

\author{
Corresponding author: \\ Wilbert S. Aronow MD, FACC, \\ FAHA \\ Department of Cardiology \\ Westchester Medical \\ Centre and New York \\ Medical College \\ Macy Pavilion \\ Room 141, Valhalla \\ NY 10595, USA \\ Phone: (914) 493-5311 \\ Fax: (914) 235-6274 \\ E-mail: wsaronow@aol.com
}


ascites, hepatic encephalopathy (HE), and hepatorenal syndrome (HRS) are known to be associated with patients diagnosed with cirrhosis [3]. Oesophageal varices progress in approximately $50 \%$ of patient with cirrhosis, and their presence correlates with the severity of liver disease [4]. In cirrhotic patients, oesophageal variceal bleeding (OVB) occurs at an annual rate of $5 \%$ to $15 \%$ and results in substantial morbidity and mortality [4]. Liver cirrhosis may be associated with a coagulopathy, and such patients are often excluded from randomised clinical trials of oral anticoagulation (OAC) therapy for stroke prevention in atrial fibrillation (AF) [5]. AF is the most prevalent arrhythmia worldwide, with an estimate to affect about 6-12 million people in the USA by 2050 and 17.9 million in Europe by 2060 [6]. One in three hospital discharges is known to account for AF [7]. In addition, several reports have suggested that AF might complicate the clinical course of patients during surgical and medical treatment [6].

Previous studies have shown predictors of OVB among patients with cirrhosis. Specifically, Hassanien et al. reported that the in-hospital mortality was particularly high among patients with acute variceal bleeding [8]. They also reported OVB and active bleeding on index endoscopy, associated major comorbidity were highly predictive of mortality [8]. However, there are limited data on the epidemiology and effects of AF in patients undergoing treatment for OVB. To date, no previous study has specifically examined the impact of AF among patients diagnosed with OVB.

To this point, the aim of the current study was to compare clinical outcomes such as mortality among patients diagnosed as having OVB with AF and without AF.

\section{Material and methods}

\section{Data sources and study population}

In this retrospective analysis, data were extracted from the 2016 and 2017 National Inpatient Sample (NIS). The NIS database is sponsored by the Agency for Healthcare Research and Quality as a part of the Healthcare Cost and Utilisation Project (HCUP) and is the largest publicly available all-payer administrative database, containing data on more than 7 million hospitalisations (unweighted); when weighted, it represents about 35 million hospitalisations nationally. It provides information on clinical and resource utilisation with safeguards to protect data for individual patients, physicians, and hospitals. Beginning in October 2015, the NIS started using the International Classification of Diseases, Tenth Edition, Clinical Modification/Procedure Coding System (ICD-10CM/PCS) to reflect the implementation of ICD-10-
CM/PCS by hospital systems. Using the Agency for Healthcare Research and Quality sampling and weighting method, national estimates of the entire US hospitalised population was calculated [9].

\section{Study design}

Given the de-identified nature of the NIS data, our study was exempt from approval from the Institutional Review Board. We identified all patients ( $\geq 18$ years of age) who had a principal diagnosis of OVB $(n=80,325)$, using their respective ICD-10-CM/PCS codes. We divided the total sample into two groups: OVB with AFIB $(n=4,285)$ and patients with EV only $(n=76,040)$. We identified patients with AFIB using appropriate diagnosis codes.

\section{Primary predictors}

For baseline characteristics, we used patient demographics (age, race, and sex), the Charlson Comorbidity Index, insurance status, hospital characteristics, and relevant co-morbidities: coronary artery disease (CAD), hypertension (HTN), obesity, dyslipidaemia, diabetes mellitus (DM), peripheral vascular disease (PVD), anaemia, chronic kidney disease, chronic lung disease, and congestive heart failure (CHF) (Table I).

\section{Clinical outcomes}

The primary outcome of interest was all-cause in-hospital mortality and predictors of mortality. Secondary outcomes included the incidence of acute kidney injury (AKI) requiring dialysis, sepsis, disseminated intravascular coagulation (DIC), venous thromboembolism, pacemaker insertion, haemorrhage requiring blood transfusion, acute coronary syndrome, shock requiring vasopressors, acute respiratory failure, and mechanical ventilation. Complications were identified using their respective ICD-10-CM/PCS. We also studied the length of hospital stay (LOS) and average hospital costs.

\section{Statistical analysis}

We conducted all statistical analyses as per the recommended methods accounting for the intricate survey design of the NIS database [10]. Categorical data are reported as frequency and percentage, and continuous data as mean with standard deviation and standard error. Categorical variables were analysed using Pearson's $\chi^{2}$ test, and continuous variables were analysed using Student's t-test. Unadjusted odds ratios for the primary and secondary outcomes were calculated using bivariable logistic regression. Multivariable logistic regression models were utilised to adjust 
Table I. Demographics comparing oesophageal variceal bleeding with atrial fibrillation vs. oesophageal variceal bleeding only

\begin{tabular}{|c|c|c|c|}
\hline Variable & OVB with AF (\%) & OVB without AF (\%) & $P$-value \\
\hline Total & 4285 & 76040 & \\
\hline Age (mean \pm SD) & $67.6 \pm 11.7$ & $55.5 \pm 12.6$ & $<0.001^{*}$ \\
\hline Female & 34.4 & 32.8 & 0.34 \\
\hline \multicolumn{4}{|l|}{ Race: } \\
\hline Caucasian (\%) & 76.14 & 62.5 & \\
\hline African American (\%) & 6.3 & 7.42 & \\
\hline Hispanic (\%) & 11.3 & 21.95 & $<0.001^{*}$ \\
\hline Asian (\%) & 2.4 & 2.3 & \\
\hline Native American (\%) & 0.6 & 2.2 & \\
\hline Others (\%) & 3.1 & 3.4 & \\
\hline \multicolumn{4}{|l|}{ Hospital bed size (\%): } \\
\hline Small & 15.9 & 15.7 & 0.97 \\
\hline Medium & 29.8 & 30.1 & \\
\hline Large & 54.1 & 54.1 & \\
\hline \multicolumn{4}{|l|}{ Hospital region (\%): } \\
\hline Northeast & 15.2 & 13.9 & $0.01^{*}$ \\
\hline Midwest & 21.2 & 17.6 & \\
\hline South & 40.4 & 41.3 & \\
\hline West & 22.9 & 27 & \\
\hline \multicolumn{4}{|l|}{ Discharge: } \\
\hline Routine & 40.6 & 66.01 & $<0.001^{*}$ \\
\hline Skill Nursing Facility & 4.5 & 4.2 & \\
\hline \multicolumn{4}{|c|}{ Charlson comorbidity Index (\%): } \\
\hline 0 or 1 & 2.8 & 6.7 & \\
\hline 2 & 4.0 & 4.1 & $<0.001^{*}$ \\
\hline 3 & 93.1 & 89.08 & \\
\hline \multicolumn{4}{|l|}{ Insurance type (\%): } \\
\hline Medicare (\%) & 66.2 & 32.7 & \\
\hline Medicaid (\%) & 13.5 & 31.09 & $<0.001^{*}$ \\
\hline Private (\%) & 17.5 & 26.7 & \\
\hline Uninsured (\%) & 2.6 & 9.4 & \\
\hline Teaching hospital (\%) & 72.2 & 69.9 & 0.17 \\
\hline \multicolumn{4}{|l|}{ Chronic co-morbidity: } \\
\hline $\mathrm{DM}$ & 43.9 & 31.7 & $<0.001^{*}$ \\
\hline HTN (\%) & 34.7 & 34.8 & 0.97 \\
\hline Obesity (\%) & 14.1 & 13.7 & 0.67 \\
\hline Dyslipidaemia (\%) & 28.2 & 13.7 & $<0.001^{*}$ \\
\hline CKD (\%) & 14 & 8.4 & $<0.001^{*}$ \\
\hline CAD (\%) & 28.7 & 18.6 & $<0.001^{*}$ \\
\hline $\mathrm{CHF}(\%)$ & 15.7 & 5.1 & $<0.001^{*}$ \\
\hline Anaemia (\%) & 6.3 & 6.2 & 0.97 \\
\hline Chronic lung disease (\%) & 8.8 & 7.9 & 0.2 \\
\hline PVD (\%) & 4.0 & 1.1 & $<0.001^{*}$ \\
\hline Tobacco Smoking (\%) & 23.2 & 21.1 & 0.1 \\
\hline Alcohol use (\%) & 12.5 & 21.4 & $<0.001^{*}$ \\
\hline Blood thinners & 15.7 & 8.7 & $<0.001^{*}$ \\
\hline
\end{tabular}

*Statistically significantly different result. OVB - oesophageal variceal bleeding, AF - atrial fibrillation, DM - diabetes mellitus, HTN - hypertension, CAD - coronary artery disease, CHF - congestive heart failure, PVD - peripheral vascular disease. 
for potential confounders in the final model. Statistical significance was set at a two-sided $p$-value of < 0.05. STATA/MP 15.10 (Stata Corp LLC) was used for statistical analysis. All analyses in our study were weighted using provided discharge weights to produce national estimates. Hospital costs were inflation-adjusted for 2018 using the Consumer Price Index (provided by the U.S. Department of Labour).

To account for the differences in baseline characteristics, we used propensity score matching [11]

To establish a propensity-matched cohort, we used the treatment outcomes as the outcome variable and potential confounders as covariates. Of note, all covariates from Table I were utilised to generate a propensity score. A $1: 1$ propensity score-match was performed using a calliper width of 0.1 using the psmatch2 command. The appropriate calliper was calculated by multiplying 0.2 by the standard deviation of the logit of the propensity score. Pstest was used to generate the unmatched and matched variable. The standardised difference of $<10 \%$ checked with pbalchk command suggested adequacy of the match between two groups among the measured covariates. Multivariable regression analyses were performed using a generalised linear model using all covariates in succession in the final model, including patient-level discharge weights. We added covariates one by one in the model, and if the coefficient changed by more than $20 \%$, we included that covariate in the final model.

\section{Results}

\section{Patient demographics}

Among the 80,325 patients included in the study, only 4285 (5.4\%) had OVB with $A F$, and 76,040 (94.6\%) had OVB only. The mean age of patients having OVB with AF was 67.6 years while that of patients having OVB only was 55.5 years $(p<0.001)$. Before propensity score matching, age, race, hospital region, discharge disposition, insurance, and Charlson co-morbidity index were different among patients diagnosed as having OVB with and without AF (all $p<0.05$ ) (Table I). Similarly, the proportion of patients with a medical history of $D M, C A D, P V D$, and CHF was higher among patients having OVB and AFIB (Table I). In contrast, patients diagnosed as having OVB with AF included about $12.5 \%$ of patients with a history of alcohol use, while those without AFIB included $21.4 \%$ of patients with a history of alcohol consumption. Of note, $15.7 \%$ of patients having OVB with AF used blood thinning medications while only $8.7 \%$ patients without AFIB were using blood thinners. As shown in Table II, matching eliminated almost all significant differences in clinical characteristics, demographics, hospital characteristics, payment source, and co-morbidity prevalence between the two cohorts, with the exception of hospital region and $\mathrm{CHF}$.

\section{Primary and secondary outcomes}

On unadjusted analyses, patients having OVB with AFB had $16.1 \%$ in-hospital mortality while the rates of in-hospital mortality were comparatively low for patients without $A F$, at $9.4 \%$. Interestingly, about $39.6 \%$ patients having OVB with AF had AKI while $23.8 \%$ of patients had AKI with OVB without AF. Of note, 1 in 8 patients having OVB with AF also had sepsis. About $17.3 \%$ of patients who had OVB with AF required mechanical ventilation, while $12.4 \%$ of patients without $A F$ required mechanical ventilation. Similarly, 3.6\% of patients with OVB and AF required vasopressors, while only $1.9 \%$ of patients without AF required vasopressors (Table III).

On adjusted multivariable analyses, patients with OVB and AF had 1.3-fold greater odds of in-hospital mortality compared with patients without $\mathrm{AF}(\mathrm{OR}=1.3,95 \% \mathrm{Cl}: 1.1-1.5 ; p<0.001)$. Consistently, after propensity score matching, the results were consistent because there was a statistically significant difference in the in-hospital mortality between the two groups $(\mathrm{OR}=1.4,95 \% \mathrm{Cl}$ : 1.09-1.83; $p<0.001$ ) (Table IV). In the unmatched cohort, patients with OVB and AF had 1.4-fold higher chance of AKI compared with those without AF $(\mathrm{OR}=1.4,95 \% \mathrm{Cl}: 1.18-1.71 ; p<0.001)$. Similarly, patients diagnosed with OVB having AF had 1.3fold higher possibility of sepsis $(\mathrm{OR}=1.3,95 \% \mathrm{Cl}$ : $1.21-1.53 ; p<0.001)$ and mechanical ventilation $(\mathrm{OR}=1.3,95 \% \mathrm{Cl}: 1.07-1.7 ; p=0.01)$ compared to the OVB-only group. Consistently, after matching both the cohorts, there were higher odds of sepsis (OR $=1.4,95 \% \mathrm{Cl}: 1.1-1.8 ; p<0.001)$, AKI $(\mathrm{OR}=1.2,95 \% \mathrm{Cl}: 1.12-1.32 ; p<0.001)$, and mechanical ventilation $(\mathrm{OR}=1.2,95 \% \mathrm{Cl}$ : 1.1-1.3; $p<0.001)$. There was no difference observed with the other complications, including AKI requiring dialysis, DIC, acute respiratory failure, shock requiring vasopressor, haemorrhage requiring blood transfusion, acute coronary syndrome, and venous thromboembolism (Table IV).

\section{Predictors of in-hospital mortality}

On multivariate logistic regression analyses, old age $(\mathrm{OR}=1.06,95 \% \mathrm{Cl}: 1.05-1.07$; $p<0.001)$, $\mathrm{CHF}(\mathrm{OR}=1.7,95 \% \mathrm{Cl}:$ 1.3-2.3; $p<0.001), \mathrm{CAD}(\mathrm{OR}=1.4,95 \% \mathrm{Cl}: 1.03-1.92$; $p=0.02)$, and sepsis $(\mathrm{OR}=1.3,95 \% \mathrm{Cl}: 1.06-1.70$; $p=0.01$ ) were identified as predictors of mortality in OVB with AF (Table V). Statistical significance was observed with the mean length of stay 
Table II. Balance of covariates before and after propensity score matching

\begin{tabular}{|c|c|c|c|c|c|c|}
\hline \multirow[t]{2}{*}{ Covariates } & \multicolumn{3}{|c|}{ Before propensity matching } & \multicolumn{3}{|c|}{ After propensity matching } \\
\hline & $\begin{array}{c}\text { OVB with AF } \\
\text { (\%) }\end{array}$ & $\begin{array}{c}\text { OVB without } \\
\text { AF (\%) }\end{array}$ & $P$-value & $\begin{array}{c}\text { OVB with AF } \\
\text { (\%) }\end{array}$ & $\begin{array}{c}\text { OVB without } \\
\text { AF (\%) }\end{array}$ & $P$-value \\
\hline Mean age & $67.6 \pm 11.7$ & $55.5 \pm 12.6$ & $<0.001^{\star}$ & 68.3 & 68.2 & 0.90 \\
\hline Female & 34.4 & 32.8 & 0.34 & 34.7 & 33.4 & 0.56 \\
\hline \multicolumn{7}{|l|}{ Race: } \\
\hline Caucasian (\%) & 76.14 & 62.5 & & 76.9 & 76.8 & \\
\hline African American (\%) & 6.3 & 7.42 & & 7.1 & 7.2 & \\
\hline Hispanic (\%) & 11.3 & 21.95 & $<0.001^{*}$ & 9.9 & 10.0 & 0.86 \\
\hline Asian (\%) & 2.4 & 2.3 & & 2.0 & 1.9 & \\
\hline Native American (\%) & 0.6 & 2.2 & & 0.7 & 0.7 & \\
\hline Others (\%) & 3.1 & 3.4 & & 3.4 & 3.4 & \\
\hline \multicolumn{7}{|l|}{ Hospital bed size (\%): } \\
\hline Small & 15.9 & 15.7 & 0.97 & 15.5 & 15.3 & \\
\hline Medium & 29.8 & 30.1 & & 27.7 & 26.9 & 0.91 \\
\hline Large & 54.1 & 54.1 & & 56.7 & 57.4 & \\
\hline \multicolumn{7}{|l|}{ Hospital region (\%): } \\
\hline Northeast & 15.2 & 13.9 & & 19.7 & 31.6 & \\
\hline Midwest & 21.2 & 17.6 & $<0.001^{*}$ & 24.3 & 23.6 & $<0.001^{*}$ \\
\hline South & 40.4 & 41.3 & & 36.3 & 30.3 & \\
\hline West & 22.9 & 27 & & 19.7 & 14.5 & \\
\hline \multicolumn{7}{|l|}{ Discharge: } \\
\hline Routine & 40.6 & 66.01 & $<0.001^{\star}$ & 44.3 & 44.1 & 0.81 \\
\hline Skilled nursing facility & 4.5 & 4.2 & & 4.5 & 4.3 & \\
\hline \multicolumn{7}{|c|}{ Charlson Comorbidity Index (\%): } \\
\hline 0 or 1 & 2.8 & 6.7 & & 2.4 & 3.1 & \\
\hline 2 & 4.0 & 4.1 & $<0.001^{*}$ & 4.2 & 4.0 & 0.54 \\
\hline 3 & 93.1 & 89.08 & & 93.4 & 92.9 & \\
\hline \multicolumn{7}{|l|}{ Insurance type (\%): } \\
\hline Medicare (\%) & 66.2 & 32.7 & & 66.7 & 66.8 & \\
\hline Medicaid (\%) & 13.5 & 31.09 & $0.00^{*}$ & 13.2 & 14.1 & 0.72 \\
\hline Private (\%) & 17.5 & 26.7 & & 17.4 & 16.8 & \\
\hline Uninsured (\%) & 2.6 & 9.4 & & 2.7 & $2 . .3$ & \\
\hline Teaching Hospital (\%) & 72.2 & 69.9 & 0.17 & 72.0 & 71.4 & 0.5 \\
\hline \multicolumn{7}{|l|}{ Chronic co-morbidity: } \\
\hline $\mathrm{DM}(\%)$ & 43.9 & 31.7 & $<0.001^{*}$ & 44.9 & 44.7 & 0.88 \\
\hline HTN (\%) & 34.7 & 34.8 & 0.97 & 30.2 & 30.8 & 0.52 \\
\hline Obesity (\%) & 14.1 & 13.7 & 0.67 & 13.2 & 12.9 & 0.20 \\
\hline Dyslipidaemia (\%) & 28.2 & 13.7 & $<0.001^{*}$ & 28.0 & 28.4 & 0.86 \\
\hline CKD (\%) & 14 & 8.4 & $<0.001^{*}$ & 21.0 & 20.6 & 0.85 \\
\hline CAD (\%) & 28.7 & 18.6 & 0.00 & 31.0 & 30.9 & 0.60 \\
\hline $\mathrm{CHF}(\%)$ & 15.7 & 5.1 & $<0.001^{*}$ & 21.8 & 14.5 & $<0.001^{*}$ \\
\hline Anaemia (\%) & 6.3 & 6.2 & 0.97 & 6.3 & 6.6 & 0.76 \\
\hline Chronic lung disease (\%) & 8.8 & 7.9 & 0.2 & 8.5 & 8.4 & 0.86 \\
\hline PVD (\%) & 4.0 & 1.1 & $<0.001^{*}$ & 4.2 & 4.0 & 0.90 \\
\hline Tobacco smoking (\%) & 23.2 & 21.1 & 0.1 & 21.0 & 21.0 & 0.99 \\
\hline Alcohol use (\%) & 12.5 & 21.4 & $<0.001^{*}$ & 18.7 & 18.2 & 0.87 \\
\hline Blood thinners & 15.7 & 8.7 & $<0.001^{*}$ & 15.6 & 14.3 & 0.13 \\
\hline
\end{tabular}

*Statistically significantly different result. OVB - oesophageal variceal bleeding; AF - atrial fibrillation; DM - diabetes mellitus, $H T N$ - hypertension, CAD - coronary artery disease, CHF - congestive heart failure, PVD - peripheral vascular disease. 
Table III. Proportion of primary and secondary outcomes: OVB with AF vs. OVB alone

\begin{tabular}{|lcc|}
\hline Outcomes & $\begin{array}{c}\text { OVB with } \\
\text { AF (\%) }\end{array}$ & $\begin{array}{c}\text { OVB } \\
\text { without } \\
\text { AF (\%) }\end{array}$ \\
\hline In-hospital mortality & 16.1 & 9.4 \\
\hline AKI & 39.6 & 23.8 \\
\hline AKI requiring dialysis & 0.4 & 0.3 \\
\hline Sepsis & 12.7 & 7.4 \\
\hline DIC & 1.1 & 1.1 \\
\hline Acute respiratory failure & 8.0 & 8.0 \\
\hline Mechanical ventilation & 17.3 & 12.4 \\
\hline Pressor requirements & 3.6 & 1.9 \\
\hline ACS & 2.4 & 1.3 \\
\hline Blood requirement & 41.5 & 38.6 \\
\hline
\end{tabular}

"Statistically significantly different result. OVB - oesophageal variceal bleeding, $A F$ - atrial fibrillation, $A K I$ - acute kidney injury, $D I C$ - disseminated intravascular coagulation, ACS - acute coronary syndrome, VTE - venous thromboembolism.

(LOS) and the mean cost of care between the two groups. Higher mean LOS (7.5 \pm 7.4 vs. $6.0 \pm 7.2$, $p<0.001)$ and mean total costs $(\$ 25,452$ vs. $\$ 21,109, p<0.001)$ were observed in the OVB with AFIB group (Table VI).

\section{Discussion}

Oesophageal varices are a cause of high mortality. If bleeding OVB is left untreated, then about $95 \%$ of patients develop recurrent bleeding, which in turn increases the probability of mortality in patients with OVB [12]. OVB and AF are also common complications among cirrhotic patients. The aim of the current study was to evaluate clini- cal outcomes among patients having OVB with and without AF. Interestingly, the current study demonstrated that the patients who were diagnosed with OVB and AF had $6.7 \%$ higher rates of in-hospital mortality compared with patients having OVB without AF. Similarly, on multivariable analyses, we found patients having OVB and AF had 1.3-fold higher odds of in-hospital mortality compared with OVB patients not having AF (95\% Cl: 1.1-1.5, $p<0.001)$. In addition, there were higher odds of sepsis $(O R=1.4$, 95\% Cl: 1.1-1.8; $p<0.001)$, AKI (OR = 1.2, 95\% Cl: $1.12-1.32 ; p<0.001)$, and mechanical ventilation $(\mathrm{OR}=1.2,95 \% \mathrm{Cl}: 1.1-1.3 ; p<0.001)$ among patients with OVB and AF.

Many investigators have emphasised the high mortality from bleeding oesophageal varices in hospitalised patients with cirrhosis [13]. Pant et al. reported that cirrhotic patients with OVB were twice as likely to die compared to patients without OVB [14]. The increased mortality rates were related to the multiorgan dysfunction due to poor perfusion, infections, and haemorrhagic/ hypovolaemic shock and cardiovascular collapse, and aspiration into airway [14]. Many studies have shown AF and OVB are common among patients with gastrointestinal and liver diseases [15]. Such diseases may contribute to AF and OVB risk through various mechanisms, including autonomic modulation and inflammation [15]. However, little is known about the outcomes among patients having OVB and AF. Interestingly, the current study noted that the OVB patients also diagnosed with AF had 1.4-fold higher odds of in-hospital mortality compared to the patients without AF. Such data highlight the importance of treatment of OVB among AF patients. Consistently, Sasso et al. re-

Table IV. Comparison of primary and secondary outcomes: OVB with AF vs. OVB only

\begin{tabular}{|c|c|c|c|c|c|c|}
\hline \multirow[t]{2}{*}{ Variable } & \multicolumn{3}{|c|}{ Before propensity score matching } & \multicolumn{3}{|c|}{ After propensity score matching } \\
\hline & Odds ratio & $P$-value & $95 \% \mathrm{Cl}$ & Odds ratio & $P$-value & $95 \% \mathrm{Cl}$ \\
\hline In-hospital mortality & 1.3 & $<0.001^{*}$ & $1.1-1.5$ & 1.4 & $<0.001^{*}$ & $1.09-1.83$ \\
\hline AKI & 1.4 & $<0.001^{*}$ & $1.18-1.71$ & 1.22 & $<0.001^{*}$ & $1.12-1.32$ \\
\hline AKI requiring dialysis & 0.96 & 0.33 & $0.17-1.8$ & 1.02 & 0.87 & $0.44-1.4$ \\
\hline Sepsis & 1.3 & $<0.001^{*}$ & $1.21-1.53$ & 1.4 & $0.007^{\star}$ & $1.1-1.8$ \\
\hline DIC & 1.01 & 0.94 & $0.57-1.81$ & 1.07 & 0.87 & $0.69-2.3$ \\
\hline Acute respiratory failure & 0.99 & 0.14 & $0.58-1.08$ & 0.9 & 0.6 & $0.29-1.9$ \\
\hline Mechanical ventilation & 1.3 & $<0.001^{*}$ & $1.07-1.7$ & 1.22 & $<0.001^{*}$ & $1.12-1.32$ \\
\hline Pressor requirements & 1.18 & 0.49 & $0.73-1.9$ & 1.01 & 0.89 & $0.79-1.3$ \\
\hline ACS & 0.96 & 0.09 & $0.33-1.05$ & 1.09 & 0.09 & $0.98-4.1 .22$ \\
\hline Blood requirement & 1.08 & 0.3 & $0.92-1.2$ & 1.9 & 0.87 & $0.87-4.3$ \\
\hline VTE & 2.2 & 0.06 & $0.94-5.5$ & 1.07 & 0.20 & $0.93-1.6$ \\
\hline
\end{tabular}

*Statistically significantly different result. AKI - acute kidney Injury, DIC - disseminated intravascular coagulation, ACS - acute coronary syndrome, VTE - venous thromboembolism. 
Table V. Predictors of mortality in OVB with AF

\begin{tabular}{|c|c|c|c|}
\hline Variable & Odds ratio & $P$-value & $95 \% \mathrm{Cl}$ \\
\hline Age & 1.06 & $<0.001^{*}$ & $1.05-1.07$ \\
\hline Congestive heart failure & 1.7 & $<0.001^{*}$ & $1.3-2.3$ \\
\hline Coronary artery disease & 1.4 & $0.02^{*}$ & $1.03-1.92$ \\
\hline Sepsis & 1.3 & $0.01^{*}$ & $1.06-1.70$ \\
\hline
\end{tabular}

*Statistically significantly different result.

Table VI. Analysis for total cost and length of stay

\begin{tabular}{|lccc|}
\hline Parameter & $\begin{array}{c}\text { Oesophageal variceal } \\
\text { bleeding with AF (\%) }\end{array}$ & $\begin{array}{c}\text { Oesophageal variceal } \\
\text { bleeding without AF (\%) }\end{array}$ & $P$-value \\
\hline Mean LOS [days] & $7.5 \pm 7.4$ & $6.0 \pm 7.2$ & $<0.001^{*}$ \\
\hline Mean total cost [\$] & 25,452 & 21,109 & $<0.001^{*}$ \\
\hline
\end{tabular}

"Statistically significantly different result. LOS - length of stay.

ported two of 59 patients had fatal bleeding from oesophageal varices, and about $56 \%$ of patients were on anticoagulation therapy for AF [16]. However, patients with a history of OVB had 5.7-fold higher odds of clinically relevant bleeding within 6 months of initiation of anticoagulation therapy [16]. This was consistent with studies of patients on anticoagulation, demonstrating fatal bleeding rates to be $0.5-5 \%$ [17]. In contrast, Kuo et al. revealed that patients with liver cirrhosis would have a positive net clinical benefit for oral anticoagulation when used for stroke prevention in atrial fibrillation [5]. However, this treatment plan should be used with caution among patients with a history of OVB. Therefore, the data collectively suggest that the patients with OVB and AF had a higher possibility of in-hospital mortality, and they emphasise that anti-coagulation therapy treatment for patients with AF and history of OVB should be adopted with caution [16]. In addition, universal guidelines should be made and adopted for the treatment of patients with OVB and AF.

OVB and AF are commonly associated with advanced liver disease, which in turn increases the susceptibility of the patients to bacterial infections. Many studies have associated endotoxaemia [18] with failure to control variceal bleeding [18], more early variceal rebleeding, abnormalities in coagulation [19], and worsening liver function. Similarly to previous studies, the current study shows that patients diagnosed with OVB and AF had 1.4-fold greater odds of having sepsis compared to patients with OVB without AF. Similarly to the current study, Borzio et al. also reported that bacterial infection, regardless of the aetiology, is a severe complication of decompensated cirrhosis, and, although frequently asymptomatic, it accounts for both longer hospital stay and increased mortality [20]. Zuo-Hua et al. also report- ed that bacterial infections increase the severity of OVB and also increase the rebleeding rate [21]. Therefore, the increased rates of sepsis might also be one of the many reasons for the worse mortality rates among patients with OVB and AF.

Many studies have revealed the predictors of mortality among patients diagnosed with OVB [22]. Specifically, Cherian et al. noted low platelet count, Child-Pugh class B/C, and spleen diameter as non-endoscopic predictors of OVB [22]. Another study revealed that patients with portal vein thrombosis and congenital hepatic fibrosis were 6.15-fold more likely to have oesophageal varices than cirrhotic patients [23]. To this point, the current study revealed that predictors of mortality among patients having OVB and AF were age, $\mathrm{CHF}, \mathrm{CAD}$, and sepsis. Consistently, a literature review by Luna et al. demonstrated that among 886 cases of oesophageal varices, about 76 patients had CHF [24]. The mechanism of development of varices among CHF or CAD is known to be on the basis of suprahepatic venous obstruction [25]. Consecutively, an abnormally elevated vena caval pressure coexists with cardiac hypertrophy, and this pressure is transmitted to the hepatic bed leading to oesophageal varices among patients with CHF, in turn leading to mortality [24]. Overall, the current data highlight important predictors of mortality among patients with OVB and AF.

There are several limitations that should be considered when analysing the results of the current study. As with any study utilising administrative databases, the results may have been affected by coding accuracy. As with any retrospective study, selection bias was possible regarding how patients were selected. However, all possible ICD10 codes were utilised to capture patients diagnosed with OVB and AF. In addition, information regarding clinical characteristics are not captured 
in the NIS dataset. However, all available important covariates have been adjusted in the multivariable analyses.

In conclusion, patients diagnosed with OVB and AF had $6.7 \%$ higher rates of in-hospital mortality compared with patients having OVB without AF. In addition, there were higher odds of sepsis, AKI, and mechanical ventilation among patients with OVB and AF. The data collectively suggest that the patients with OVB and AF had a greater likelihood of in-hospital mortality, and they emphasise that universal guidelines should be made and adopted for the treatment of patients with OVB and AF. We recommend further research to understand the important clinical predictors of mortality among patients with OVB and AF.

\section{Acknowledgments}

All authors had access to the data and played a role in contributing to this manuscript. Pavani Garlapati, Ebad Ur Rahman, and Vijay Gayam contributed equally to this study.

\section{Conflict of interest}

The authors declare no conflict of interest.

\section{References}

1. Orman ES, Roberts A, Ghabril M, et al. Trends in characteristics, mortality, and other outcomes of patients with newly diagnosed cirrhosis. JAMA Netw Open 2019; 2: e196412.

2. Mokdad AA, Lopez AD, Shahraz S, et al. Liver cirrhosis mortality in 187 countries between 1980 and 2010: a systematic analysis. BMC Med 2014; 12: 145.

3. Nusrat S, Khan MS, Fazili J, Madhoun MF. Cirrhosis and its complications: evidence based treatment. World J Gastroenterol 2014; 20: 5442-60.

4. Duah A, Nkrumah KN, Tachi K. Oesophageal varices in patients with liver cirrhosis attending a major tertiary hospital in Ghana. Pan Afr Med J 2018; 31: 230.

5. Kuo L, Chao TF, Liu CJ, et al. Liver cirrhosis in patients with atrial fibrillation: would oral anticoagulation have a net clinical benefit for stroke prevention? J Am Heart Assoc 2017; 6: e005307.

6. Miyasaka Y, Barnes ME, Gersh BJ, et al. Secular trends in incidence of atrial fibrillation in Olmsted County, Minnesota, 1980 to 2000, and implications on the projections for future prevalence. Circulation 2006; 114: 119-25.

7. Malmo V, Langhammer A, Bonaa KH, Loennechen JP, Ellekjaer $\mathrm{H}$. Validation of self-reported and hospital-diagnosed atrial fibrillation: the HUNT study. Clin Epidemiol 2016; 8: 185-93.

8. Hassanien M, El-Talkawy MD, El-Ghannam M, El Ray A, Ali AA, Taleb HA. Predictors of in-hospital mortality in patients with hepatocellular carcinoma and acute variceal bleeding. Electron Physician 2015; 7: 1336-43.

9. HCUP. https://www.hcup-us.ahrq.gov/. 19 ${ }^{\text {th }}$ August, 2020.

10. Khera R, Angraal S, Couch T., et al. Adherence to methodological standards in research using the national inpatient sample. JAMA 2017; 318: 2011-8.
11. D’Agostino RB Jr. Propensity scores in cardiovascular research. Circulation 2007; 115: 2340-3.

12. Krige JE, Kotze UK, Bornman PC, Shaw JM, Klipin M. Variceal recurrence, rebleeding, and survival after endoscopic injection sclerotherapy in 287 alcoholic cirrhotic patients with bleeding esophageal varices. Ann Surg 2006; 244: 764-70.

13. Myers RP, Papay KD, Shaheen AA, Kaplan GG. Relationship between hospital volume and outcomes of esophageal variceal bleeding in the United States. Clin Gastroenterol Hepatol 2008; 6: 789-98.

14. Pant C, Desai M, Deshpande A, Taylor R, Olyaee M, Gilroy R. Esophageal variceal bleeding in hospitalized patients with cirrhosis. J Hosp Med 2015; 10: 453-6.

15. Long MT, Ko D, Arnold LM, et al. Gastrointestinal and liver diseases and atrial fibrillation: a review of the literature. Therap Adv Gastroenterol 2019; 12: 1756284819832237.

16. Sasso R, Rockey DC. Anticoagulation therapy in patients with liver cirrhosis is associated with an increased risk of variceal hemorrhage. Am J Med 2019; 132: 758-66.

17. Rubboli A, Becattini C, Verheugt FW. Incidence, clinical impact and risk of bleeding during oral anticoagulation therapy. World J Cardiol 2011; 3: 351-8.

18. Hou MC, Lin HC, Liu TT, et al. Antibiotic prophylaxis after endoscopic therapy prevents rebleeding in acute variceal hemorrhage: a randomized trial. Hepatology 2004; 39: 746-53.

19. Montalto P, Vlachogiannakos J, Cox DJ, Pastacaldi S, Patch D, Burroughs AK. Bacterial infection in cirrhosis impairs coagulation by a heparin effect: a prospective study. J Hepatol 2002; 37: 463-70.

20. Borzio M, Salerno F, Piantoni L, et al. Bacterial infection in patients with advanced cirrhosis: a multicentre prospective study. Dig Liver Dis 2001; 33: 41-8.

21. Zuo-Hua G, Chen-Chi T, Kuo-Chih T, Chih-Chun T, Yu-Hsi H, Tsung-Hsing H. The effect of bacterial infections in cirrhotic patients with esophageal variceal bleeding. Ann Hepatol 2014; 13: 364-9.

22. Cherian JV, Deepak N, Ponnusamy RP, Somasundaram A, Jayanthi V. Non-invasive predictors of esophageal varices. Saudi J Gastroenterol 2011; 17: 64-8.

23. Fagundes ED, Ferreira AR, Roquete ML, et al. Clinical and laboratory predictors of esophageal varices in children and adolescents with portal hypertension syndrome. J Pediatr Gastroenterol Nutr 2008; 46: 178-83.

24. Luna A, Meister HP, Szanto PB. Esophageal varices in the absence of cirrhosis, Incidence and characteristics in congestive heart failure and neoplasm of the liver. Am J Clin Pathol 1968; 49: 710-7.

25. Cardenas A, Gines P. Portal hypertension. Curr Opin Gastroenterol 2009; 25: 195-201. 